\title{
Development and Validation of HPLC Method for the Simultaneous Determination of Insecticides (Carbofuran and Fipronil) in its Technical and Granular Formulation
}

\author{
Salman Khurshid ${ }^{1}$, Saba Iqbal*1 ${ }^{1}$, Nasreen Fatima ${ }^{2}$, Saqib Arif ${ }^{1}$, Maaz Khurshid ${ }^{3}$ \\ Mehwish Iqbal $^{1}$, Qurrat-ul-Ain Akber ${ }^{1}$, Riaz-ud-Din ${ }^{1}$ and Shahid Yousaf ${ }^{1}$ \\ ${ }^{*}$ Food Quality \& Safety Research Institute, SARC, PARC, Karachi, Pakistan. \\ ${ }^{2}$ Department of Chemistry, University of Karachi, Pakistan. \\ ${ }^{3}$ Department of Earth \& Environmental Sciences, Bahria University Islamabad, Pakistan. \\ *Corresponding Author Email: sabaiqbal190@gmail.com \\ Received 26 October 2020, Revised 04 November 2020, Accepted 04 November 2020
}

\begin{abstract}
A precise, accurate, simple and low cost reverse phase high performance liquid chromatographic (RP-HPLC) method was developed and validated for the simultaneous quality assessment of commonly used insecticide carbofuran and fipronil in its technical and formulated products. The chromatographic parameters, i.e. mobile phase composition, wavelength and flow rate of developed method was optimized in such a way that the HPLC was carried out at $280 \mathrm{~nm}$ by using a mobile phase, which contains 80 parts acetonitrile and 20 parts water by volume $\left(\mathrm{ACN}: \mathrm{H}_{2} \mathrm{O}\right.$, 80:20) flowing at a rate of $1.0 \mathrm{~mL} / \mathrm{min}$. A linear relationship $\left(\mathrm{R}^{2}>0.999\right)$ was shown by calibration curve plotted in the concentration ranged from $30-800 \mathrm{mg} / \mathrm{L}$. The limit of detection (LODs) were found to be $14.5 \mathrm{mg} / \mathrm{L}$ and $20.9 \mathrm{mg} / \mathrm{L}$ and limit of quantification (LOQs) were recorded to be $43.9 \mathrm{mg} / \mathrm{L}$ and $63.2 \mathrm{mg} / \mathrm{L}$ for both carbofuran and fipronil respectively. The developed method's accuracy was exhibited by recovery percentage (96.0-100.8) \% of water samples spiked with 100, 300 and $600 \mathrm{mg} / \mathrm{L}$ of carbofuran and fipronil, respectively. The developed RP-HPLC method is therefore simple, cheap, rapid and can be proficiently used for the simultaneous identification and quantification of carbofuran and fipronil in its technical and formulated products.
\end{abstract}

Keywords: Carbofuran, Fipronil, Quantification, HPLC, Validation

\section{Introduction}

A noticeable increase in the usage of pesticide has been observed during the last few decades in advancing agricultural development to meet the consumption rate per capita [1]. Currently available formulations are composed of approximately eight hundred and sixty (860) active ingredients sold commercially [2]. These plant protection products (pesticides) play a significant role in the field of agriculture to meet international requirements for food security and quality [3]. Irrespective of the economy, the excessive use of pesticide causes severe damages to the environment as well as crops. The aim of the protection policy at European and National level is to lessen risks associated with the use of pesticides [4]. Quality control and assessment of these chemical substances is the foremost step in this esteem. Pesticide products are sold in various formulations i.e. granular, solutions, emulsions, aerosols and dry solids due the differences in physical, chemical, handling, 
transportation and ability to control the target [5].

Pesticides are mainly classified on the basis of toxicity, chemical composition, mode of action, formulations and source of origin etc. On the basis of chemical composition pesticides specifically insecticides are classified as organochorine, organophosphorus, carbamate, and pyrethroids. Among all other pesticides, carbofuran and fipronil are commonly used insecticides. A highly toxic carbamate pesticide namely carbofuran is widely used in agriculture [6]. Although their use is prohibited in US [7], but it is still permitted in Pakistan, and it is extensively used in a number of crops such as wheat, cotton, rice, sugarcane, cabbage, potatoes, tomatoes and lettuce. In mammals, Acetylcholinesterase (AchE), which is responsible to catalyze hydrolysis of the neurotransmitter acetylcholine $(\mathrm{ACH})$ is reversibly inhibited by 3-hydroxycarbofuran. Carbofuran poisoning results in vomiting, excessive sweating, high blood pressure, breathing difficulties, diarrhea, blurred vision, nausea and fatal at high dosages due to respiratory failure [6]. Fipronil belongs to a chemical family of phenyl pyrazole was first synthesized by Bayer Crop Science (Old name: Rhône Poulenc Ag, Co, 1987) introduced for use and registered in the US in 1993 and 1996, respectively [2]. It contains a trifluoromethylsulfinyl group that may contribute to its notable effectiveness in the field. A distinct advantage of fipronil is that it is one of the most selective and effective in small amounts in the field against insects which show resistance to pyrethroids, organophosphates (OP) and carbamic acid derivative insecticides [8]. It is a wide-range insecticide against contact and eating pests as well as many species of insects are controlled by fipronil, when crops such as vegetables, fruits and rice experience an insecticides attack [9].
To manage a number of samples, analytical laboratories are working to reduce the retention time at each step of the method [10]. In order to speed up the monitoring and quality control process, there is a need for simple, quick, cheap and eco-friendly analytical method for quantitative analysis of these chemical substances to reduce the run time of analysis per sample. In this aspect, HPLC is considered as the most preferable technique in pesticide monitoring affairs. Marczewska et al., 2020 [11] developed a novel method for the concurrent analysis of azoxystrobin and its relative impurity present in available pesticide SC (Suspension Concentrate) formulation through HPLCDAD. Hafeez et al., [12] also reported an HPLC method for the simultaneous analyses of dimethomorph and chlorothalonil. The present study is aimed to develop an easy, fast and eco-friendly RP-HPLC method with UVVis detection for the concurrent analysis of carbofuran and fipronil in pesticide formulated products by using RP-HPLC coupled with UV-Vis detector available in almost all laboratories dealing with the pesticides and pharmaceutical samples etc. This newly developed method was further validated for system suitability testing, linearity, precision, accuracy and robustness. The most prominent edge of developed method was that both active ingredients i.e. carbofuran and fipronil with quite different classes and polarities were simultaneously analyzed using fast and accurate procedures.

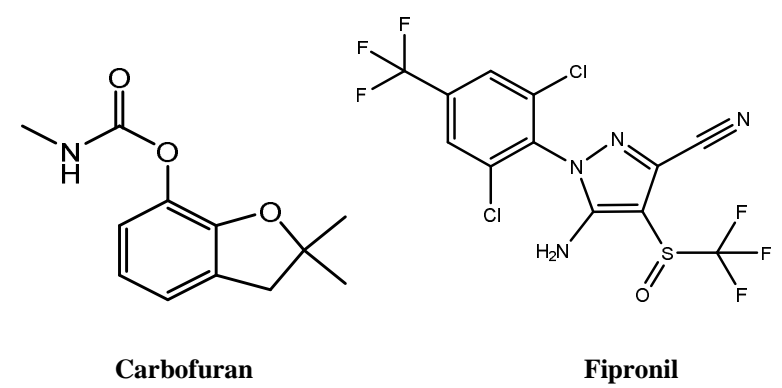

Figure 1. Chemical structure of selected active ingredients 
Material and Methods

Chemicals and Reagents

Analytical grade solvents (methanol and acetonitrile) were purchased from RCI LabScan delivered by M/s Nawaid Scientific Traders, Karachi used throughout the experiments. Analytical standard of carbofuran and fipronil (Fig. 1) of purity $\geq$ 98\% were obtained from department of Plant Protection, Malir, Karachi while technical grade and their respective pesticide formulations were obtained from Warble (Pvt). Ltd. Multan, Pakistan.

\section{Instrumentation}

HPLC was used throughout the developmental procedure. The HPLC system comprised of a SHIMADZU 10A Series associated with UV-visible detector (SPD10AV) having changeable wavelength. Mobile phase was pumped towards column with pressure pumps LC-10AT. HPLC system was further integrated with Chemstation CSW 1.7 Japan. The separation of chromatogram was attained on RP (reversed phase) supelco C18 column $(5 \mu, 250 \times 0.46 \mathrm{~mm})$.

\section{Chromatographic Conditions and Method optimization}

Liquid chromatographic parameters of the method were optimized by testing various mobile phase composition, flow rate and wavelength. Different mobile phases of Acetonitrile $(\mathrm{ACN})$ or Methanol $(\mathrm{MeOH})$ with water at intervals of $10 \mathrm{~mL}$ (50:50-100:00) were exercised to optimize the mobile phase ratio. The injection volume was fixed to 20 $\mu \mathrm{L}$. The variation in the mobile phase flow rate was exercised in the range of (0.5-1) $\mathrm{mL} / \mathrm{min}$ and wavelength was set at $280 \mathrm{~nm}$. Each solvent of mobile phase was filtered through $0.45 \mu \mathrm{m}$ filter paper followed by degassing through ultra-sonication. The separation of the analyte was accomplished by using C18 supelco column $(5 \mu, 250 \times 0.46$ $\mathrm{mm})$. According to Hafeez et al., [12] wavelength were varied between 200-300 nm with an interval of $10 \mathrm{~nm}$ to determine the optimum wavelength considering specificity towards the tested analyte.

\section{Preparation of Stock Standards}

Standard stock solutions for both carbofuran and fipronil were prepared by accurately weighing $0.25 \mathrm{~g}$ of reference standards in $25.0 \mathrm{~mL}$ volumetric flask and were diluted up to the mark with mobile phase (ACN: $\mathrm{H}_{2} \mathrm{O}, 80: 20$ ) to prepare 1000 ppm stock solutions. These standard stock solutions were kept in dark at $4{ }^{\circ} \mathrm{C}$ and were used for the preparation of working standard solutions.

\section{Preparation of Working Standards}

For calibration curve, six working standard solutions were prepared from standard stock solutions using mobile phase (ACN: $\mathrm{H}_{2} \mathrm{O}, 80: 20$ ) for each analyte in the range of $30-800 \mathrm{mg} / \mathrm{L}$. Each of the six standard solutions of both analytes (carbofuran and fipronil) were then analysed in triplicates.

\section{Preparation of Sample Solutions}

For the preparation of sample solution from formulated pesticides products, $0.01 \mathrm{~g}$ of commercially available insecticides carbofuran and fipronil were both accurately weighed and transferred to $25.0 \mathrm{~mL}$ volumetric flask and diluted up to the mark with mobile phase (ACN: $\left.\mathrm{H}_{2} \mathrm{O}, 80: 20\right)$. The resulting solutions were sonicated for $10 \mathrm{~min}$. The solutions were then filtered through 0.45 micron Millipore PTFE membrane filter before injection into the HPLC system. The sample solutions were used within $3 \mathrm{~h}$ after preparation to minimize the degradation. 
Results and Discussion Development and Optimization of Method

There are a number of analytical methods available for the quantitative analysis of carbofuran and fipronil but these methods demand different chromatographic conditions i.e. mobile phase and flow rate etc. Therefore, an effort was made to propose an analytical method for carbofuran and fipronil for their consistent and simultaneous quantitative determination in its technical formulated products. The developed method is highly efficient as compared to method reported by Junior et al., in terms of cost effectiveness and simple with attuned chromatographic conditions using HPLC coupled with UVvisible detector [13]. ICH guidelines were followed to validate the developed method [14]. Symmetrical peaks with good separation of analyte and high resolutions (Table 1) were obtained by using mobile phase $\left(\mathrm{ACN}: \mathrm{H}_{2} \mathrm{O}\right.$, $80: 20)$ at a flow rate $1.0 \mathrm{~mL} / \mathrm{min}$ and wavelength $280 \mathrm{~nm}$. A representative chromatogram for carbofuran and fipronil is shown in the Fig. 2 with no peak interference as compared to the study reported by others [12].

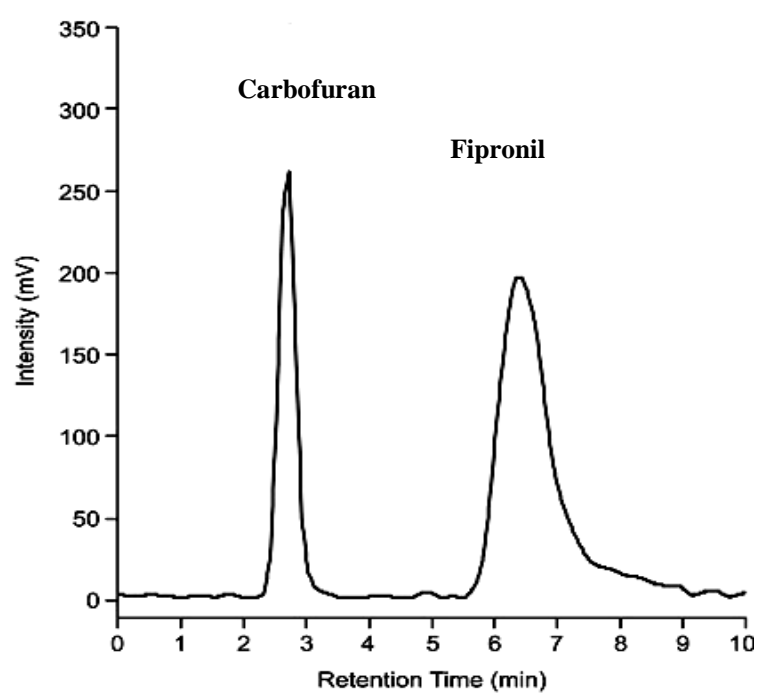

Figure 2. Representative chromatogram of carbofuran and fipronil

\section{Method Validation}

The proposed method permits the analyte(s) to elute within $2.7 \pm 0.1$ and $6.4 \pm$ $0.2 \mathrm{~min}$ with total runtime of $10 \mathrm{~min}$. to completely elute the residue of the analyte to reproduce smooth baseline. To validate this method, several parameters such as linearity, LODs and LOQs, accuracy, precision and robustness were studied.

\section{System Suitability Testing}

For system suitability testing, ten replicates of both carbofuran and fipronil were carried out to check the resolution and other technical parameters required for method development. The results of the system suitability test given in the Table-1 were in agreement with the standard parameter of system suitability test given by Pharmacopeia and FAO $[15,16]$.

Table 1. System suitability testing for carbofuran and fipronil.

\begin{tabular}{|c|c|c|c|c|c|}
\hline $\begin{array}{l}\text { Active } \\
\text { ingredient }\end{array}$ & RT $\quad K^{\prime}$ & $\begin{array}{c}\text { Inter } \\
\text { repeatability } \\
\text { (\% } \mathrm{RSD})\end{array}$ & TP & Resolution & TF \\
\hline Carbofuran & $2.7 \quad 2.09$ & 0.55 & 12429 & 9.77 & 1.21 \\
\hline Fipronil & 6.42 .13 & 0.55 & 13034 & 7.07 & 1.14 \\
\hline
\end{tabular}

\section{Linearity}

The linearity of the developed method was demonstrated by analyzing six working standards of different concentrations. The calibration curve of carbofuran and fipronil were constructed between concentrations $(\mathrm{mg} / \mathrm{L})$ versus detector response $(\mathrm{mV})$ in the concentration range of $30-800 \mathrm{mg} / \mathrm{L}$, the curve was found to be linear with $\mathrm{R}^{2}$ values greater than 0.999 as per the ICH guidelines [14], a $\left(\mathrm{R}^{2}>0.998\right)$ value is an acceptable fit of data to the regression line. 
Table 2. Analytical parameters of linearity, LoD and LoQ.

\begin{tabular}{lcccccc}
\hline $\begin{array}{l}\text { Active } \\
\text { Ingredient }\end{array}$ & $\begin{array}{c}\text { Calibration } \\
\text { Level }\end{array}$ & Slope & $\begin{array}{c}\text { Inter- } \\
\text { cept }\end{array}$ & $\mathbf{R}^{2}$ & $\begin{array}{c}\text { LoD } \\
(\mathbf{m g} / \mathbf{L})\end{array}$ & $\begin{array}{c}\text { LoQ } \\
(\mathbf{m g} / \mathbf{L})\end{array}$ \\
\hline Carbofuran & 6 & $0.24 x$ & +2.8 & 0.999 & 20.9 & 63.2 \\
Fipronil & 6 & $0.27 x$ & +1.0 & 0.999 & 14.5 & 43.9 \\
\hline
\end{tabular}

\section{LODs and LOQs}

ICH guidelines were followed to determine the detection limits (LODs) and quantification (LOQs) of the proposed method by using standard deviation $(\sigma)$ and their slopes (S). Standard deviation and slope values were determined from calibration curves. The following equation is used to calculate LODs and LOQs respectively

$$
\begin{aligned}
& \mathrm{LOD}=3.3 \sigma / \mathrm{S} \\
& \mathrm{LOQ}=10 \sigma / \mathrm{S}
\end{aligned}
$$

LODs and LOQs of the proposed method are given in (Table 2) for both carbofuran and fipronil, respectively. The limit of detection and quantification calculated for fipronil in the current study were significantly closed with value obtained by Hafeez et al., [12].

\section{Accuracy}

The developed method accuracy was demonstrated as per ICH guidelines [14], by taking a different pesticide concentration 100 , 300 and $600 \mathrm{mg} / \mathrm{L}$, prepared from the standard stock solutions of $1000 \mathrm{mg} / \mathrm{L}$. As indicated in the Table 3 , the recovery range for carbofuran and fipronil were found in between 98.5-100.5 and $96.0-100.8 \mathrm{mg} / \mathrm{L}$ with standard deviation less than $5 \%$, respectively $[13,16]$. Both these parameters indicated that the developed method was quite acceptable in terms of accuracy. Percent recovery of carbofuran obtained through the developed HPLC method were comparable to the HPLC-DAD method published by Junior et al. 2017 [13].

Table 3. Accuracy of method.

\begin{tabular}{lcccc}
\hline $\begin{array}{l}\text { Active } \\
\text { ingredient }\end{array}$ & $\begin{array}{c}\text { Reference } \\
\text { value } \\
(\mathbf{m g} / \mathbf{L})\end{array}$ & $\begin{array}{c}\text { Actual } \\
\text { value } \\
(\mathbf{m g} / \mathbf{L})\end{array}$ & $\begin{array}{c}\text { Recovery } \\
(\%)\end{array}$ & $\begin{array}{c}\text { Mean } \\
\text { recovery } \\
(\%) \\
(\mathbf{n = 9 )}\end{array}$ \\
\hline Carbofuran & 300 & $298.7 \pm 0.87$ & $99.6 \pm 0.13$ & $99.5 \pm 0.09$ \\
& 600 & $603.2 \pm 0.51$ & $100.5 \pm 0.04$ & \\
& 100 & $96.0 \pm 0.060$ & $96.0 \pm 0.06$ & \\
Fipronil & 300 & $301.1 \pm 0.76$ & $100.4 \pm 0.25$ & $99.0 \pm 0.06$ \\
& 600 & $605.0 \pm 1.10$ & $100.8 \pm 0.18$ & \\
\hline
\end{tabular}

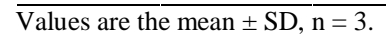

\section{Precision}

As it is well known that the precision is an indicator of repeatability of results over the period of time. For the determination of the precision of the developed method, 250 $\mathrm{mg} / \mathrm{L}$ of the stock solution were used and six replications of each active ingredient were made on the same day (day 1) as well as on three different days for assessing inter and the intraday precision of the results. As clear from the Table 4 the, \%RSD of the method was less than $1 \%$, which indicated that the developed method was highly precise $[12,14]$.

\begin{tabular}{|c|c|c|c|c|c|c|c|c|}
\hline \multirow{3}{*}{$\begin{array}{l}\text { Active } \\
\text { ingredient }\end{array}$} & \multicolumn{6}{|c|}{ Intra-day precision } & \multicolumn{2}{|c|}{ Inter day precision } \\
\hline & \multicolumn{2}{|c|}{ Day 1} & \multicolumn{2}{|c|}{ Day 2} & \multicolumn{2}{|c|}{ Day 3} & \multirow[b]{2}{*}{$\begin{array}{l}\text { Actual value } \\
\quad(\mathrm{mg} / \mathrm{L})\end{array}$} & \multirow[b]{2}{*}{$\% R S D$} \\
\hline & $\begin{array}{c}\text { Actual value } \\
(\mathrm{mg} / \mathrm{L})\end{array}$ & $\% R S D$ & $\begin{array}{c}\text { Actual value } \\
(\mathrm{mg} / \mathrm{L})\end{array}$ & $\% R S D$ & $\begin{array}{l}\text { Actual value } \\
(\mathrm{mg} / \mathrm{L})\end{array}$ & $\% R S D$ & & \\
\hline Carbofuran & 248.40 & 0.06 & 247.50 & 0.14 & 247.40 & 0.14 & 247.76 & 0.13 \\
\hline Fipronil & 248.93 & 0.09 & 248.62 & 0.10 & 248.07 & 0.17 & 248.54 & 0.11 \\
\hline
\end{tabular}

Table 4. Intra-day and inter-day precision.

Values are the mean, $n=6$

Reference concentration of analyte $(\mathrm{s})=250 \mathrm{mg} / \mathrm{L}$ 


\section{Robustness}

Robustness is related with an ability of method to remain unchanged when minor alterations in the parameters of method are applied. It is considered as an indicator that reflects the reliability of the method. The developed method robustness were checked by making changes in the ratio of mobile phase $\pm 2 \mathrm{~mL}$, flow rate $\pm 0.1 \mathrm{~mL} / \mathrm{min}$ and wavelength $\pm 2 \mathrm{~nm}$, respectively $[12,14]$. Table 5 shows that small deliberate changes in mobile phase composition, flow rate and wavelength have negligible effect on the overall chromatographic responses. Thus the developed method was found to be robust.

Table 5. Robustness of Method.

\begin{tabular}{|c|c|c|c|c|c|}
\hline \multirow[b]{2}{*}{ Parameters } & \multirow[b]{2}{*}{ Variables } & \multicolumn{2}{|c|}{ Carbofuran } & \multicolumn{2}{|c|}{ Fipronil } \\
\hline & & $\begin{array}{c}R T \\
(\min )\end{array}$ & $P A$ & $\begin{array}{c}R T \\
(\min )\end{array}$ & $P A$ \\
\hline \multirow{3}{*}{$\begin{array}{l}\text { Mobile } \\
\text { phase ratio } \\
\left(\mathrm{ACN}: \mathrm{H}_{2} \mathrm{O}\right)\end{array}$} & $78: 22$ & $2.8 \pm 0.3$ & $34.9 \pm 0.4$ & $6.5 \pm 0.4$ & $34.0 \pm 0.1$ \\
\hline & $80: 20$ & $2.7 \pm 0.1$ & $34.7 \pm 0.2$ & $6.4 \pm 0.1$ & $33.9 \pm 0.3$ \\
\hline & $82: 18$ & $2.5 \pm 0.2$ & $34.5 \pm 0.4$ & $6.2 \pm 0.5$ & $33.5 \pm 0.4$ \\
\hline \multirow{3}{*}{$\begin{array}{l}\text { Flow rate of } \\
\text { mobile } \\
\text { phase } \\
\text { (mL/min) }\end{array}$} & 0.9 & $2.9 \pm 0.4$ & $34.9 \pm 0.2$ & $6.6 \pm 0.3$ & $34.0 \pm 0.2$ \\
\hline & 1.0 & $2.7 \pm 0.1$ & $34.7 \pm 0.2$ & $6.4 \pm 0.1$ & $33.9 \pm 0.3$ \\
\hline & 1.1 & $2.6 \pm 0.2$ & $34.5 \pm 0.4$ & $6.2 \pm 0.1$ & $33.7 \pm 0.4$ \\
\hline \multirow{3}{*}{$\begin{array}{l}\text { Detector } \\
\text { Wavelength } \\
\text { (nm) }\end{array}$} & 278 & $2.8 \pm 0.3$ & $35.0 \pm 0.0$ & $6.5 \pm 0.2$ & $34.2 \pm 0.5$ \\
\hline & 280 & $2.7 \pm 0.1$ & $34.7 \pm 0.2$ & $6.4 \pm 0.1$ & $33.9 \pm 0.3$ \\
\hline & 282 & $2.6 \pm 0.4$ & $34.5 \pm 0.1$ & $6.3 \pm 0.5$ & $33.2 \pm 1.0$ \\
\hline
\end{tabular}

\section{Conclusion}

An isocratic HPLC method for the simultaneous assessment of carbofuran and fipronil in pesticide formulated products has been successfully developed. The developed method was further analysed by assessing different validation parameters of ICH guidelines. The linearity of the method was determined in the concentration ranged from $30-800 \mathrm{mg} / \mathrm{L}$ with $\left(\mathrm{R}^{2}=0.999\right)$ for both carbofuran and fipronil. LODs and LOQs of the method obtained through the data of linearity were found to be $20.9-14.5 \mathrm{mg} / \mathrm{L}$ and 63.2-43.9 $\mathrm{mg} / \mathrm{L}$ for carbofuran and fipronil, respectively. The proposed method was further ensured with good accuracy and precision. The overall results obtained suggest that the developed method can be used effectively for the quantitative analysis of active ingredients (carbofuran and fipronil) available in its technical and formulated products.

\section{Acknowledgement}

Authors of the manuscript are thankful to their laboratory staff for providing continuous assistance throughout the bench work.

\section{References}

1. T. Skevas, A. O. Lansink and S. E. Stefanou, NJAS-Wageningen J. Life Sci., 64 (2013) 95.

doi: 10.1016/j.njas.2012.09.001

2. C. Tomlin, The Pesticide Manual, $12^{\text {th }}$

Ed. British Crop Protection Council, Farnham, Surrey, UK, (2000). ISBN 19013961269781901396126

3. H. Karasali and N. Maragou, Encyclopedia of Food and Health, (2016) 319.

doi:10.1016/B978-0-12-3849472.00535-3

4. J. Bürger, F. de Mol and B. Gerowitt, Crop Protect., 27 (2008) 343. doi: 10.1016/j.cropro.2007.06.006

5. M. Sarwar, Cogent Med., (2016) 3: 1155373.

doi:10.1080/2331205X.2016.115537 $\underline{3}$

6. C. G. Ramesh, J. Toxicol. Environ. Health, Part A, 43 (1994) 383. doi:10.1080/15287399409531931

7. L. NovotnýL, J. Misík, A. Honzlová, P. Ondráček, K. Kuča, O. Vávra, V. 
Rachač and P. Chloupek, J. Appl. Biomed., 9 (2011) 157.

doi: 10.2478/v10136-009-0035-3

8. A. Bobé, C. M. Coste and J. -F. Cooper, J. Agric Food Chem., 45 (1997) 4861.

doi: 10.1021/jf970362z

9. H. Collins and A. Callcott, Florida Entomol., 8 (1998) 407.

doi: $10.2307 / 3495930$

10. M. Tankiewicz and M. Biziuk, Anal. Bioanal. Chem., 410 (2018) 1533. doi: 10.1007/s00216-017-0798-4

11. P. Marczewska, M. Płonka, J. Rolnik and M. Sajewicz, J. Environ. Sci. Health Part B, 55 (2020) 599. doi:10.1080/03601234.2020.1746572

12. A. Hafeez, I. A. Tawab and S. Iqbal, $J$. AOAC Int., 99 (2016) 1185. doi: 10.5740/jaoacint.16-0108
13. V. G. Junior, N. Q. Hazarbassanov, A. de Siqueira, J. C. Florio, C. H. P. Ciscato, P. C. Maiorka, A. Fukushima and $H$. de Souza Spinosa, $J$. Chromatogr. B, 1065 (2017) 8. doi: 10.1016/j.jchromb.2017.09.02

14. Guideline, I.H.T., Q2 (R1) 1 (2005). https://database.ich.org/sites/default/files IQ2_R1_Guideline.pdf(Accessed 11 Mar 2020)

15. The United States Pharmocopeial Convention Inc., $27^{\text {th }}$ Ed. Rockville, MD, USA, USP 32 NF 27, (2009) 733. doi: 10.4103/0250-474X.95653

16. Food and Agriculture Organization of the United Nations, FAO Food and Nutrition Paper 68 (1997). http://www.fao.org/3/a-w5800e.pdf (Accessed 28 Sep 2020) 